\title{
Propagation of Normal Zones in Composite Superconductors
}

\author{
Lawrence Dresner
}

\section{OAK RIDGE NATIONAL LABORATORY}




\section{DISCLAIMER}

This report was prepared as an account of work sponsored by an agency of the United States Government. Neither the United States Government nor any agency Thereof, nor any of their employees, makes any warranty, express or implied, or assumes any legal liability or responsibility for the accuracy, completeness, or usefulness of any information, apparatus, product, or process disclosed, or represents that its use would not infringe privately owned rights. Reference herein to any specific commercial product, process, or service by trade name, trademark, manufacturer, or otherwise does not necessarily constitute or imply its endorsement, recommendation, or favoring by the United States Government or any agency thereof. The views and opinions of authors expressed herein do not necessarily state or reflect those of the United States Government or any agency thereof. 


\section{DISCLAIMER}

Portions of this document may be illegible in electronic image products. Images are produced from the best available original document. 
Printed in the United States of America: Available from

National Technical Information Service

U.S. Department of Commerce

5285 Port Royal Road, Springfield, Virginia 22161

Price: Printed Copy $\$ 4.00$; Microfiche $\$ 2.25$

This report was prepared as an account of work sponsored by the United States Government. Neither the United States nor the Energy Research and Development Administration/United States Nuclear Regulatory Commission, nor any of their employees, nor any of their contractors, subcontractors, or their employees, makes any warranty, express or implied, or assumes any legal liability or responsibility for the accuracy, completeness or usefulness of any information, apparatus, product or process disclosed, or represents that its use would not infringe privately owned rights. 
ORNL/TM-5543

Contract No. W-7405-eng-26

PROPAGATION OF NORMAL ZONES IN COMPOSITE SUPERCONDUCTORS

Lawrence Dresner

Magnetics and Superconductivity Section

Thermonuclear Division

\section{AUGUST 1976}

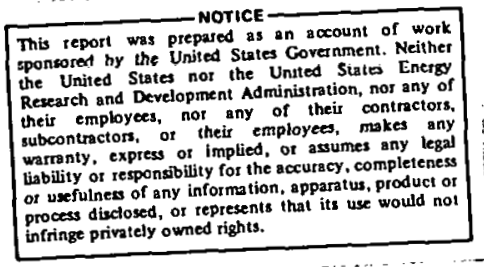

(Submitted for Publication in Cryogenics)

NOTICE This document contains information of a preliminary nature and was prepared primerlly for internal use at the Oak Ridge National Laboretory. It is subject to revision or correction and therefore does not represent a final report.

OAK RIDGE NATIONAL LABORATORY

Oak Ridge, Tennéssee 37830

UNION CARBIDE CORPORATION

for the

ENERGY RESEARCH AND DEVELOPMENT ADMINISTRATION 


\section{THIS PAGE \\ WAS INTENTIONALLY \\ LEFT BLANK}


TABLE OF CONTENTS

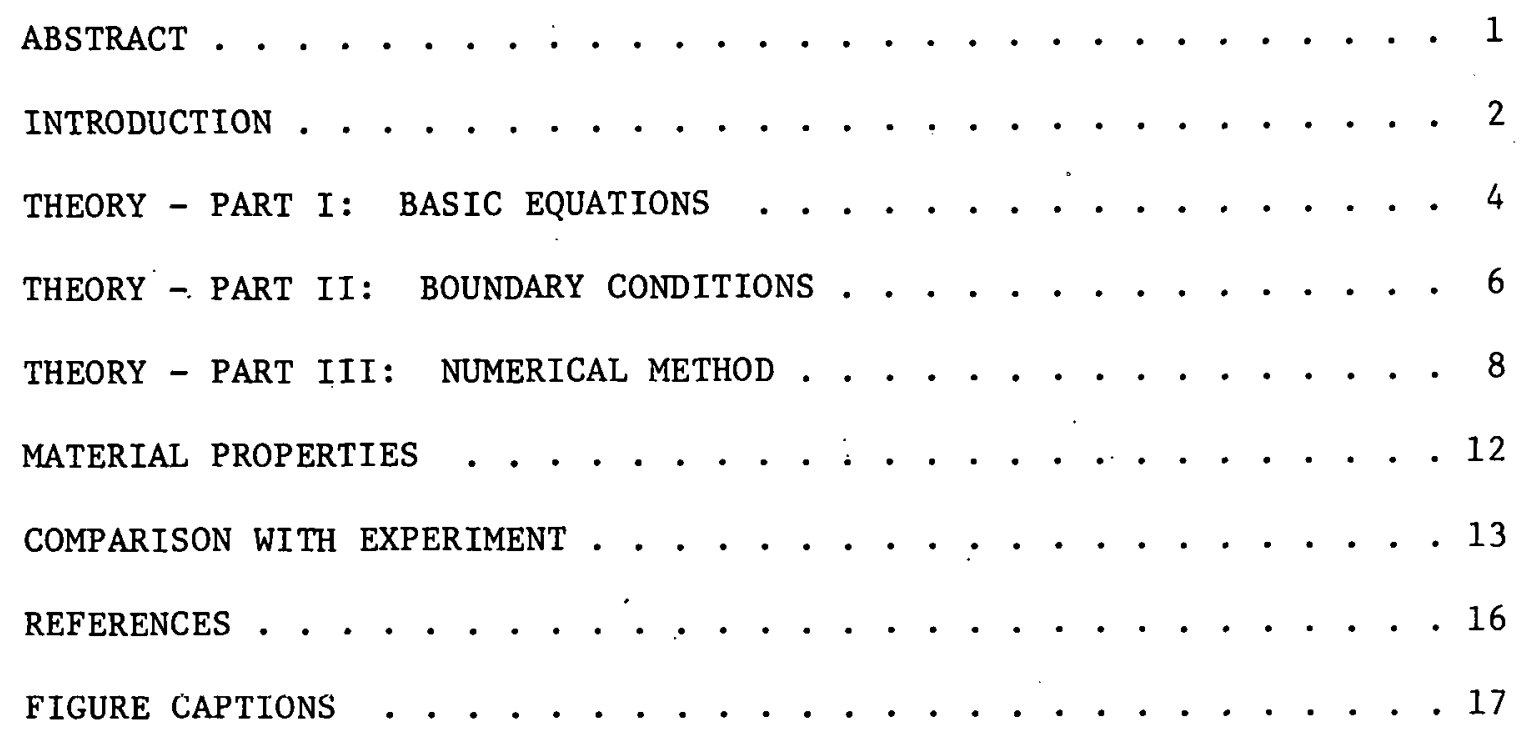


PROPAGATION OF NORMAL ZONES IN COMPOSITE SUPERCONDUCTORS*

Lawrence Dresner

Thermonuclear Division

Oak Ridge National Laboratory

Oak Ridge, Tennessee 37830

Abstract

This paper describes calculations of propagation velocities of normal zones in composite superconductors. Full accounting is made for (1) current sharing, (2) the variation with temperature of the thermal conductivity of the copper matrix, and the specific heats of the matrix and the superconductor, and (3) the variation with temperature of the steady-state heat transfer at a copper-helium interface in the nucleateboiling, transition, and film-boiling ranges. The theory, which contains no adjustable parameters, is compared with experiments on bare (uninsulated) conductors. Agreement is not good. It is concluded that the effects of transient heat transfer may need to be included in the theory to improve agreement with experiment.

${ }^{*}$ Research sponsored by the Energy Rescarch and Development Administration under contract with Union Carbide Corporation. 


\begin{abstract}
PROPAGATION OF NORMAL ZONES IN COMPOSITE SUPERCONDUCTORS*
Lawrence Dresner

Thermonuclear Division

Oak Ridge National Laburatory

Oak Ridge, Tennessee 37830
\end{abstract}

\title{
Ineroduction
}

The earliest attempts to calculate the propagation velnsity of normal zones were those of Cherry and Gittleman ${ }^{1}$ and Broom and Rhoderick ${ }^{2}$ in 1960. These authors considered propagation of a normal zone in an unclad superconductor in contact with boiling helium. Because superconductors of technological interest today are composites consisting of copper- or aluminum-clad superconducting strands, these early calculations are not of direct use. In 1967, Keilin, Klimenko, Kremlev, and Samoilev ${ }^{3}$ presented a calculation of the propagation velocity in a composite superconductor. The theory described in their paper takes into account current sharing between the substrate and the superconductor; but the results they presented were only for the case of no current sharing, i.e., the case of an instantaneous jump of all the current from the superconductor to the substrate at one point. In 1973, Altov, Kremlev, Sytchev, and Zenkevitch ${ }^{4}$ refined the results of Keilin et al. by including the effects of current sharing. Whereas all of the previous studies had produced results in the form of closed formulas, the work of Altov et al. had to be done numerically.

All of the above studies were carried out under the assumption of ${ }^{\cdot}$ constant material properties (that is to say, constant specific heat and

\footnotetext{
* Research sponsored by the Energy Research and Development Administration under contract with Union Carbide Corporation.
} 
thermal conductivity) and a constant heat transfer coefficient. Attempts were made in the past to include the temperature variation of the material properties. For example, Whetstone and Roos $^{5}$ in their calculations of propagation velocities in $\mathrm{Nb}-\mathrm{Zr}$ alloys included the temperature variation of the specific heat, the thermal conductivity, and the electrical conductivity. However, their experimental samples were potted or isolated by cellophane tape from the helium bath; and in their calculations they ignored transverse heat transfer to the helium altogether. Furthermore, their calculations referred to unclad wires and consequently did not need to take current sharing into account. Thus, while instructive, the work of Whetstone and Roos is not of direct use here.

Maddock, James, and Norris ${ }^{6}$ calculated the current at which the propagation velocity in composite superconductors changes sign, i.e., the current at which normal zones stop recovering and start propagating. They took into account the details of the heat transfer process in poolboiling helium, as well as current sharing and the temperature variation of the thermal conductivity. The only drawback of their paper is that it is limited to the calculation of only one point on the curve of propagation velocity vs series current. Their method is extremely interesting, however, and will be used as the jumping-off point of the present work.

Recently, Dresner; Miller, and Donaldson ${ }^{7}$ presented measurements and calculations of normal zone propagation in bare, insulated, and potted composite superconductors. Their calculations took into account fully current sharing and the temperature variation of the material properties, but assumed the heat transfer coefficient to be constant. When they tried to fit curves of velocity vs current, they found 
that "the experimental points for the insulated wire ... can be fitted fairly well by a single unique choice of overall heat transfer coefficient" but that "no single heat transfer coefficient can ever reproduce the experimental points for the bare wire." It seems clear from this that the next step in the comparison of theory and experiment, at least for bare conductors, is to incorporate into the theory a heat transfer coefficient more realistic than a simple constant.

This paper describes calcularlons of propagaliun velocities in composite superconductors in which this is done. Full accounting is made for (1) current sharing, (2) the variation with temperature of the thermal conductivity of the matrix (copper) and the specific heat of the matrix and the superconductor (NbTi); and (3) the variation with temperature of the heat transfer at a copper-helium surface in the nucleate-boiling, transition, and film-boiling ranges.

\section{Theory - Part 1: Kasic tquations}

We begin by writing a heat balance for a length, $\Delta x$, of a bare composite superconductor in a helium bath (see Fig. 1). The local temperature $I(x, t)$ is assumed to vary with time, $t$, and with axial position, $x$, but to be uniform in the transverse direction. The heat balance is as follows:

$$
\mathrm{A} \Delta \mathrm{xS} \quad \frac{\partial \mathrm{T}}{\partial \mathrm{t}}=\mathrm{Q}_{\mathrm{J}} \mathrm{A} \Delta \mathrm{x}-\mathrm{QP} \Delta \mathrm{x}-\mathrm{A} \Delta \mathrm{x} \frac{\mathrm{d}}{\mathrm{dx}}\left(-\mathrm{k} \frac{\mathrm{dT}}{\mathrm{dx}}\right)
$$

where
A $=$ the cross-sectional area of the conductor $\left(m^{2}\right)$
$S=$ the specific heat of the conductor per unit volume
$\left(\mathrm{J} \mathrm{m}^{-3} \mathrm{~K}^{-1}\right)\left[=\mathrm{fS}_{\mathrm{cu}}+(1-\mathrm{f}) \mathrm{S}_{\mathrm{NbTi}}\right.$, where $\mathrm{f}$ is the volume fraction of copper]


$Q_{J}=$ the Joule heat produced per unit volume of conductor
$\left(\mathrm{W} \mathrm{m}^{-3}\right)$

$\mathrm{Q}=$ the heat flux per unit surface area from the conductor into the helium $\left(\mathrm{W} \mathrm{m}^{-2}\right)$. $Q$ is a function of the temperature difference between the conductor and the helium bath.

$\mathrm{P}=$ the cooled perimeter of the conductor (m)

$k=$ the thermal conductivity of the conductor $\left(\mathrm{W} \mathrm{m}^{-1} \mathrm{~K}^{-1}\right)$ $\left(=\mathrm{f} \mathrm{k}_{\mathrm{cu}}\right)$.

We are looking for a traveling wave solution of Eq. 1 of the form $\mathrm{T}=\mathrm{T}(\mathrm{x}+\mathrm{vt})$, which represents a wave traveling from right to left (see Fig. 2). Far to the right of the wave front, $T$ is asymptotic to the constant temperature $\mathrm{T}_{\text {as }}$; far to the left of the wave front $\mathrm{T}$ is asymptotic to the temperature $T_{b}$ of the helium. For such a traveling wave $\partial \mathrm{T} / \partial t=v \partial \mathrm{T} / \partial \mathrm{x}$, and Eq. 1 becomes

$$
\frac{d}{d x}\left(k \frac{d T}{d x}\right)-v S \frac{d T}{d x}+\left(Q_{J}-\frac{Q P}{A}\right)=\cdot 0
$$

At this point we note that the last term on the right, $Q_{J}-Q P / A$, depends explicitly only on temperature. We can, therefore, reduce the order of this differential equation by one by using the substitution of Maddock, James, and Norris: ${ }^{6}$

$$
\mathrm{s}=\mathrm{k} \frac{\mathrm{dT}}{\mathrm{dx}}
$$

Equation 2 then becomes

$$
s \frac{d s}{d T}-v S s+k\left(Q_{j}-\frac{Q P}{A}\right)=0
$$


The voltage drop in the distance $\Delta x$ is $I_{c u} \rho \Delta x / f A$, where $I_{c u}$ is the part of the series current I flowing in the conductor. In the superconducting region, $I_{c u}=0$; in the normal region, $I_{c u}=I$; and in the current sharing region, $I_{c u}$ can be calculated from the assumed linear relation between critical current and temperature: ${ }^{6}$

$$
\frac{I_{c r}(T)}{I_{C I}\left(T_{b}\right)}=\frac{T_{c r}-T}{T_{C r}-T_{b}}
$$

Since the voltage drop in the superconductor is the same as that in the copper,

$$
A \Delta Q_{J}=I\left(\frac{I_{c u} \rho \Delta x}{f A}\right)
$$

or

$$
U_{J}=\frac{I\left(I_{C u}\right) \rho}{f A^{2}}
$$

Then Eq. 4 becomes

$$
s \frac{d s}{d T}-v S s+\frac{k_{b} P}{T_{b} A} T\left[\frac{I\left(I_{c u}\right) \rho}{f A P}-Q\right]=0
$$

where we have taken $k$ to be equal to $k_{b} T / T_{b}$, and where $k_{b}$ is the value of $k$ at $T=T_{h} \cdot{ }^{6}$ More will be said about this assumption in a later section.

\section{Theory - Part II: Boundary Conditions}

Far to the left of the propagating front, the temperature of the conductor approaches the constant value $T_{b}$. There $s=0$. The last term on the right must then also vanish. It does: for when $T=T_{b}, I_{c u}=0$ and $Q=0$. 
Far to the right of the propagating front, the temperature approaches the constant value $\mathrm{T}_{\text {as }}$. Again $\mathrm{s}=0$, and the first two terms in Eq. 7 vanish. Hence $\mathrm{T}_{\text {as }}$ is one of the solutions of the equation

$$
\frac{I\left(I_{\mathrm{cu}}\right) \rho}{\mathrm{fAP}}=Q
$$

Equation 8 always has an even number of solutions, i.e., $0,2,4$ (see Fig. 3). When more than one solution exists, we must determine which one to use: This we do by first noting that the solutions of Eq. 8 are the equilibrium points of Eq. 1 and that not all of them are stable. Only stable solutions of $\mathrm{Eq} .8$ can be used.

We linearize Eq. 1 in order to see which solutions of Eq. 8 are stable:

$$
\mathrm{S} \cdot \frac{\partial(\delta \mathrm{T})}{\partial \mathrm{t}}=\frac{\mathrm{P}}{\mathrm{A}}\left[\frac{\mathrm{d}}{\mathrm{dT}} \cdot\left(\frac{\mathrm{I}\left(\mathrm{I}_{\mathrm{cu}}\right) \rho}{\mathrm{fAP}}-\mathrm{Q}\right)\right] \delta \mathrm{T}+\mathrm{k} \frac{\mathrm{d}^{2}}{\mathrm{dx}^{2}}
$$

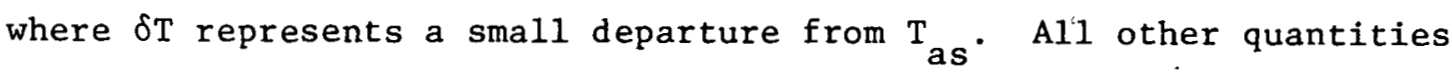
are evaluated at $\mathrm{T}=\mathrm{T}_{\text {as }}$. If we impose a perturbation $\delta \mathrm{T}$ that is proportional to $\cos (\kappa x)$ or $\sin (\kappa x)$, we find

$$
S \frac{\partial \delta T}{\partial t}=\left\{\frac{P}{A}\left[\frac{d}{d T}\left(\frac{\left.I_{c u}\right) \rho}{f A P}-Q\right)\right]_{T=T}-k K^{2}\right\} \delta T
$$

The perturbation will die away if

$$
\frac{\mathrm{d}}{\mathrm{dT}}\left(\frac{\mathrm{I(I_{ \textrm {cu } } ) \rho}}{\mathrm{fAP}}-\mathrm{Q}\right)_{\mathrm{T}=\mathrm{T}}<\frac{\mathrm{A}}{\mathrm{P}} \mathrm{kK} \mathrm{K}^{2}
$$


Otherwise it will grow. The only solutions of Eq. 8 that are stable against all perturbations are those for which the left side of Eq. 11 is negative, i.e., those solutions at which the curve of heat production I ( ( $\left._{\mathrm{cu}}\right) \rho / f A P$ crosses from above the curve of heat loss $Q$ to below it with increasing temperature. Thus in Fig. 3 only the points marked with arrows are stable solutions of Eq. 8 .

Since $d Q / d T<0$ in the transition boiling range, while the slope of the heat production curve is always $\geq 0$, no stable equilibrium solution of Eq. 8 can occur in the transition boiling range. However, as Maddock, James, and Norris ${ }^{6}$ point out, all temperatures between $T_{b}$ and $T_{\text {as }}$ occur in the temperature profile at the wave front; for $\mathrm{dT} / \mathrm{dx}$ must not be infinite at any point in order to prevent the axial heat flux from becoming infinite.

The experiments analyzed in this paper correspond to either Fig. 3(a) or Fig. 3(d).

\section{Theory - Part III: Numerical Method}

We must solve the differential equation. (7) under the boundary conditions (1) $s=0$ at $T=T_{b}$ and (2) $s=0$ at $T=T_{a s}$. These boundary conditions can only be satisfied simultaneously for the correct value of v. We find the correct value of $v$ by trial and error. We assume a value of $v$ and integrate from $T_{\text {as }}$ to $T_{b}$. If $v$ is too small, $s$ will be positive over the (open) interval $\mathrm{T}_{\mathrm{b}}<\mathrm{T}<\mathrm{T}_{\mathrm{as}}$. If $\mathrm{v}$ is too large, $\mathrm{s}$ will change sign somewhere in this interval. Only for the correct $v$ will s be zero at $\mathrm{T}=\mathrm{T}_{\mathrm{b}}$ as well as at $\mathrm{T}=\mathrm{T}_{\text {as }}$.

In order to start a numerical integration of Eq. 7 , we need a value of $s$ away from the equilibrium point $T=T_{\text {as }}, s=0$. We get one by 
solving Eq. 7 in a small enough neighborhood of $\mathrm{T}$ around $\mathrm{T}_{\text {as }}$ that we can use the lowest-order non-vanishing approximation to the coefficients:

$$
s \frac{d s}{d \tau}-v_{a s} s-\frac{k_{b} P}{T_{b} A} T_{a s}\left(\frac{d Q}{d T}\right)_{a s} \tau=0
$$

where $\tau=\mathrm{T}-\mathrm{T}_{\text {as }}$ and the subscript "as" indicates that the quantity should be evaluated at $\mathrm{T}_{\text {as }}$. [The derivative of $\mathrm{I}_{(\mathrm{cu}}$ ) $\mathrm{f} / \mathrm{fAP}$ drops out, since $I_{c u}$ is constant and equal to $I$ in the neighborhood of $T=T_{a s}$. This equation has the form

$$
8 \frac{d s}{d \tau}-a s-b \tau=0
$$

where $a$ and $b$ are constant positive coefficients. given by comparison with Eq. 12. If we introduce a new variable $y$, equal to $s / \sqrt{b}$, we find

$$
\frac{d y}{d \tau}=m+\frac{\tau}{y}, m=\frac{a}{\sqrt{b}}
$$

Owing to the nonlinearity of Eq. $12 \mathrm{~b}$, the best way to study its solutions is to plot its direction field, part of which is shown in Fig. 4 for $m=1$. The derivative $d y / d \tau=\infty$ when $y=0 ; d y / d \tau=0$ on the Iine $L_{0}: y=-\tau / m ;$ and $d y / d \tau=m$ when $\tau=0$. The derivative $\mathrm{dy} / \mathrm{d} \tau=\mathrm{y} / \tau$ on two perpendicular straight lines $\mathrm{L}_{+}$and $\mathrm{L}_{-}$with respective slopes $\frac{1}{2}\left(m \pm \sqrt{m^{2}+4}\right)$. These two lines are integral curves of the differential equation $(12 b)$. All other integral curves lie entirely in one of the four quadrants defined by $\mathrm{L}_{*}$ and $\mathrm{L}_{-}$, and asymptotically approach each of them. $L_{+}$and $L_{-}$are the only integral curves which pass through the point $(0,0)$. Since we are looking for the one for which $s>0$ when $\tau<0$, we choose $L_{-}$. Hence we choose some point on this line as our starting value, e.g., 
$\tau=-|\mathrm{dT}|, s=\frac{\tau}{2} \sqrt{\mathrm{b}}\left(\mathrm{m}-\sqrt{\mathrm{m}^{2}+4}\right)$, where $\mathrm{dT}=-|\mathrm{dT}|$ is the temperature increment used in the stepwise integration of Eq. $8 \mathrm{~b}$.

There is a difficulty with this straightforward procedure. As m grows larger, the slopes of the lines $L_{0}$ and $L_{-}$grow smaller and the two lines approach each other very closely. For example, in Fig. 4 (for which the scales on the $y$ - and $\tau$-axes are the same) $L_{0}$ and $L$ are inclined at angles of $45^{\circ}$ and $32^{\circ}$ to the $\tau$-axes, respectively. For $m=4$, these two angles are $14.0^{\circ}$ and $13.3^{\circ}$, respectively, and for $\mathrm{m}=10$, they are $5.65^{\circ}$ and $5.71^{\circ}$, respectively. When $\mathrm{L}_{0}$ and $\mathrm{L}_{-}$are very close together and close to the negative $\tau$-axis, starting the numerical integration of Eq. $12 \mathrm{~b}$ at $\tau=-|\mathrm{dT}|$ may lead to the development of an instability. The instability is caused by the rapid change of slope $d y / d \tau$ which occurs near the origin in the region included between $\mathrm{L}_{\mathrm{o}}$ and the $\tau$-axis. Taking a starting point further along the line $L_{\text {_ }}$ avoids the instability; and because the integral curves eventually approach the line $L_{-}$as an asymptote, once away from the neighborhood of the origin the integration is very stable. A similar difficulty occurs in the integration of Eq. 7 and a similar remedy has been used, viz., the integration is started at $\mathrm{T}=\mathrm{T}$ as $-\mathrm{n}|\mathrm{dT}|, \mathrm{s}=\frac{-\mathrm{n}|\mathrm{dT}|}{2} \sqrt{\mathrm{b}}\left(\mathrm{m}-\sqrt{\mathrm{m}^{2}+4}\right)$, where $\mathrm{n}$ is a sufficently large integer to assure stability.

Shown in Fig. 5 are typical curves of $s$ vs $T$ obtained by Runge-Kutta integration of Eq. 7, starting as described above. When the assumed propagation velocity is too small, the curves remain above the axis for all $\mathrm{T}<\mathrm{T}_{\mathrm{as}}$. For the correct value of $\mathrm{v}$, the curve of $s$ vs $T$ would just fall to zero at $T=T_{b}$. If $v$ is too large, the curve intersects the $T$-axis at some point $T>T_{b}$. Once the curve 
has crossed the $\mathrm{T}$-axis there is no reason to continue the integration, since the solution again becomes unstable.

To see this we again expand Eq. 7 , this time around $T=T_{b}$. Since $I_{c u}=0$ in small neighborhoods of $T_{b}$, the behavior of the last term in Eq. 7 is governed by the behavior of Q. In general, Q decreases with decreasing $\tau=T-T_{b}$ more rapidly than would a linear function, let us say it decreases as $Q_{0} \tau^{c}$, where $c>1$. Then, near $T=T_{b}$,

$$
s \frac{d s}{d \tau}-v S_{b} s-\frac{k_{b} P}{A} Q_{o} \tau^{c}=0 .
$$

which can be reduced to the form

$$
\frac{d y}{d \tau}=m+\frac{\tau^{c}}{y}, c>1
$$

We are interested in Eq. $13 \mathrm{~b}$ only for $\tau \geq 0$.

The derivative $d y / d \tau=0$ for $y=-\tau^{c} / m$ (curve $L_{0}$ in Fig. 6); $\mathrm{dy} / \mathrm{d} \tau=\infty$ for $\mathrm{y}=0$; and $\mathrm{dy} / \mathrm{d} \tau=\mathrm{m}$ for $\tau=0$. The derivative $\mathrm{dy} / \mathrm{d} \tau$ can only change sign on the $\tau$-axis and on the curve $L_{0}$; since it is positive on the y-axis, it must be positive everywhere above the $\tau$-axis and in the reginn hetween the negative y-axis and the curve $L_{0}$. Elsewhere $\mathrm{dy} / \mathrm{d} \tau<0$. There are three families of integral curves as shown in Fig. 6; they are separated by two separatrices $S_{1}$ and $S_{2}$, which are the only integral curves to pass through the origin.

We are interested in finding the integral curve of Eq. 7 which becomes $S_{2}$ near $T=T_{b}$. If we choose a value of $v$ too small, the curve of $s$ vs $\tau$ lies above $S_{2}$ and thus remains positive right down to $\tau=0$. On the other hand, if $v$ is too large, the curve of $s$ vs $\tau$ lies below $s_{2}$. For a sufficiently small value of $\tau$ the curve of $s$ vs $\tau$ crosses the $\tau-$ axis with infinite slope. Owing to the occurrence of very large slopes, 
any finite-difference integration scheme becomes inaccurate near the crossing. However, any change in sign of $s$ from positive to negative will be a signal that $\mathrm{v}$ is too large.

\section{Material Properties}

We take the temperature dependence of the material properties to be the following:

(1) Electrical Resistivicy. In the experiments analyzed bere, the maximum temperature of the conductor $\mathrm{T}_{\text {as }}$ was $\lesssim 20 \mathrm{~K}$. We have therefore taken the resistivity of the copper matrix to be independent of temperature over the temperature range of interest in normal-zone propagation.

(2) Thermal Conductivity. The thermal conductivity of copper is taken to vary directly with temperature, in accordance with the WiedemannFranz Law, which is assumed to apply in the background magnetic field. 8

(3) Specific Heat. The specific heat of copper is taken as $0.628 \times 10^{-2} \mathrm{~T}+0.859 \times 10^{-3} \mathrm{~T}^{3}\left(\mathrm{~J} \mathrm{~kg}^{-1} \mathrm{~K}^{-1}\right) .^{9}$ The specific heat of $\mathrm{NbTi}$ has been taken from measurements of Zbasnik $^{10}$ done at zero field for $\mathrm{Nb}-48.8 \mathrm{wt} \% \mathrm{Ti}$. If we assume that the thermodynamic critical field of the superconductor varies linearly with temperature (which it does for temperatures close to the zero-field critical temperature), it is then possible, using thermodynamic arguments, to calculate the sperifir. heat at non-zero magnetic fields. Figure 7 shows the results of such calculations at 4 and $8 \mathrm{~T}$. The superconducting-normal transition is shown as if it were sharp, although experimentally it is spread over. several tenths of a degree.

(4) Heat Transfer at Helium-Copper Surface. Steady-state heat transfer in pool boiling is a complicated matter; and it is by no means clear that steady-state heat transfer coefficients rather than transient 
heat transfer coefficients are the correct choice. In the experiments analyzed here, the transition zones at the normal front are only a few centimeters long. With propagation velocities of a few meters per second, the zones pass a fixed point in a few tens of milliseconds at most. Experiments on transient heat transfer ${ }^{11-12}$ have shown that for a given temperature difference, the heat fluxes which may be sustained for times as short as this are much higher than those which occur in steady state.

We do not have enough information to prescribe a curve of transient heat flux vs temperature difference, but we do have enough information to prescribe a curve of steady-state heat flux vs temperature. By use of the experimental steady-state curve, we obtain a model for comparison with experiment in which all the required data are known and for which all the calculations can be done accurately. Comparison of this model with experiment will tell us at once whether transient heat transfer is important or not.

There is wide variation even in steady-state heat transfer data, due to variations in the orientation and condition of the surface. In this paper we use three reported curves of heat flux vs temperature, viz., those of Brentari and Smith, ${ }^{13}$ of Butler et al., ${ }^{14}$ and of Lyon ${ }^{15}$ (see Fig. 8).

\section{Comparison with Experiment}

Shown in Fig. 9 are plots of measured propagation velocities vs current, based on data reported in Ref. 7 for a $5.1 \times 10^{-4}$-m-diameter, 348-strand composite conductor with a $\mathrm{Cu} / \mathrm{SC}$ volume ratio of $1.9: 1$. The resistivity of the copper was measured as $2.6 \times 10^{-10} \mathrm{ohm}-\mathrm{m}$ at zero field; at a field of $6.5 \mathrm{~T}$, at which the velocities were measured, the 
resistivity is increased by the magneto-resistive effect to $6.06 \times 10^{-10} \mathrm{ohm}-\mathrm{m} .{ }^{16}$ The critical current has been taken from the measurements of Hampshire et al, ${ }^{17}$ and is $53 \mathrm{~A}$.

Shown also are five curves labeled with numbers. These curves are taken from Ref. 7 and are calculations performed with constant heat transfer coefficients equal (in $\mathrm{W} \mathrm{cm}^{-2}$ ) to the labeling numbers. In addition there are three curves, labeled (a), (b), and (c), that have been calculated by the method of this paper using the boiling heat transfer curves of Brentari and Smith, Butler et al., and Lyon.

Neither family of curves agrees well with the experimental points. This seems to be an unequivocal indication that steady-state heat transfer coefficients are inadequate to describe the growth of normal zones (except possibly for very small velocities of propagation).

We can make a crude test of this conclusion by arbitrarily modifying the heat transfer curves in some way intended to simulate transient heat transfer. 'lhere is included in F1g. 9 a docted curve obtained by modifylng the heat transfer coefficient of Brentari and Smith by the factor $\exp \left[\ln 2\left(T_{a s}-T\right) /\left(T_{a s}-T_{b}\right)\right]$. This causes the heat transfer coefficient to be twice as great as the steady-state value at the head of the transition zone and to approach the steady-state value far behind the transition zone. Agreement is much improved; and it seems clear that a velocity-dependent correction that increases with velocity could improve agreement even more. Further exertions in this direction seem unwarranted because they involve so much arbitrariness.

Finally, one more thing needs to be taken into account, namely, the latent heat of the normal-superconducting transition. When a superconductor goes from the superconducting state to the normal state 
in the presence of an external magnetic field, it absorbs heat. Normal zones grow by axial conduction of heat from the normal towards the superconducting material. The absorption of latent heat by the superconductor decreases this axial transport. Inclusion of the latent heat in the theory should decrease the propagation velocity.

The amendment necessary to the theory already given is simple. At the temperature $T_{C r}(B)$ there is a step change in s given by

$$
s_{s c}=s_{n}-v \ell(1-f)
$$

where the subscripts indicate the superconducting and normal sides of the moving boundary at $T=T_{c r}(B)$, and $l$ is the latent heat per unit volume of superconductor. The latter can be calculated under the same assumptions as stated earlier for the calculation of the specific heat, with the following result:

$$
\ell=\Delta S\left[T_{c r}(B)\right]\left[T_{c r}(B=0)-T_{c r}(B)\right]
$$

where $S$ is now the specific heat per unit volume of superconductor, $\Delta S$ is the jump in $S$ at the transition temperature $T_{c r}(B)$, and $T_{c r}(B=0)$ is the transition temperature at zero external magnetic field.

When the effects of the latent heat modify curve A in Fig. 9, the velocity is decreased everywhere by a factor of 1.2 , i.e., the slope of line $A$ is decreased by a factor of 1.2 . This is a small reduction compared with the reduction by a factor of 2.9 necessary to get agreement with theory. The effects of the latent heat thus appear to be small. Nevertheless, their inclusion is no burden on the theory and is recommended. It seems clear that the major cause of the discrepancy between theory and experiment is the effect of transient heat transfer. 
References

1. Cherry, W. H., Gittelman, J. T. Solid-State Electron. 1 (1960) 287

2. Broom, R. F., Rhoderick, E. H. Br. J. App1. Phys. 11 (1960) 292

3. Keilin, V. E., Klimenko, E. Yu., Kremlev, M. G., Samoilev, N. B. in Les Champs Magnetiques Intenses, (CNRS, Paris, 1967) 231

4. Altov, V. V., Kremlev, M. G., Sytchev, V. V., Zenkevitch, V. B. Cryogenics $13(1.973) 420$

5. Whetsluite, C. N., Rüus, C. F. J. App1. Pliys. JG (1965) 703.

6. Maddock, B. J., James, G. B., Norris, W. T. Cryogenics 9 (1969) 261

7. Dresner, L., Miller, J. R., Donaldson, G. W. "Propagation of Norma1 Zones in Composite Superconductors," paper presented at the 6 th Symposium on Engineering Problems of Fusion Research, San Diego, Calif., Nov. 18-21, 1975.

8. Fevrier, A., Morize, D. Cryogenics 13 (1973) 603.

9. Materials Research for Superconducting Machinery II, (NBS-ARPA, October 1974)

10. Zbasnik, J. quoted in Iwasa, Y., Weggel, C., Montgomery, D. B., Weggel, R., Hale, J. R. J.Appl. Phys. 40 (1969) 2006

11. Jackson, J. Cryogenics 9 (1969) 103

12. Tsukamoto, 0., Kobayshi, S. J.App1. Phys. 46 (1975) 1359

13. Brentari, E. G., Smith, R. Y. "Nucleate and Film Pool Boiling Design Correlations for $\mathrm{O}_{2}, \mathrm{~N}_{2}, \mathrm{H}_{2}$, and He," in International Advances in Cryogenic Engineering, [Timmerhaus, $\bar{K}$. D. (ed)] (P1enum Press, New York, 1965) vo1. 10

14. Butler, A. R., James, G. B., Maddock, B. J., Norris, W. T. Int1. Journal of Heat and Mass Transfer 13 (1970) 105

15. Lyon, quoted in Superconducting Magnet Systems, by. H. Brechna (Springer Verlag, New York, 1973) Fig. 5.7.11, p. 452

16. According to a Köhler plot privately communicated by F. R. Fickett (Cryogenics Division, NBS, Boulder, Colorado) to C. J. Long (ORNL).

17. Hampshire, R., Sutton, J., Taylor, M. T. Proc. Conf. on Low Temperatures and Electric Power, (London, 1969) 69 


\section{Figure Captions}

Fig. 1. Sketch describing the heat balance for a length $\Delta x$ of a bare conductor.

Fig. 2. Sketch of the traveling temperature wave in the conductor.

Fig. 3. Sketch showing the steady states of a conductor in a pool of boiling helium. The ordinate has the dimensions of heat per unit volume; the abscissa is the temperature elevation above the helium bath temperature. The heavy line is the heat loss to the helium; the light line is the Joule heat production. The arrows mark the stable states.

Fig. 4. Sketch of the direction field and integral curves of Eq. 12b.

Fig. 5. Part of a family of integral curves obtained by numerical integration of Eq. 7, showing the variation with increasing propagation velocity.

Fig. 6. Sketch of the direction field and integral curves of Eq. 13b.

Fig. 7. Calculated specific heat of $\mathrm{Nb}-48.8$ wt $\% \mathrm{Ti}$ as a function of temperature and magnetic field.

Fig. 8. Boiling correlations of Brentari and Smith, Lyon, and Butler et al. Fig. 9. Comparison of theory and experiment. 
ORNL-DWG 76-4276

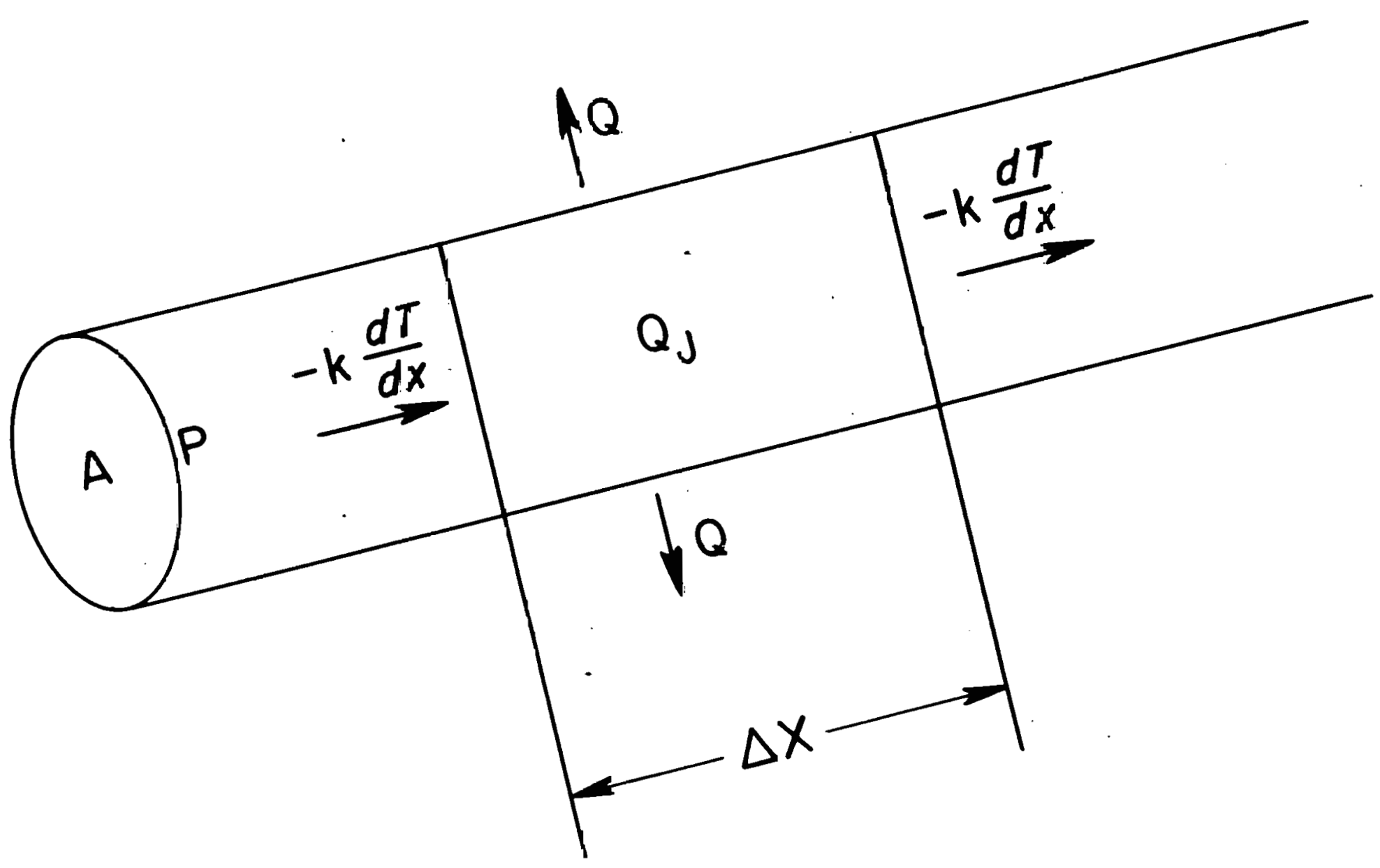

FIGURE 1 


\section{ORNL-DWG 76-4275}

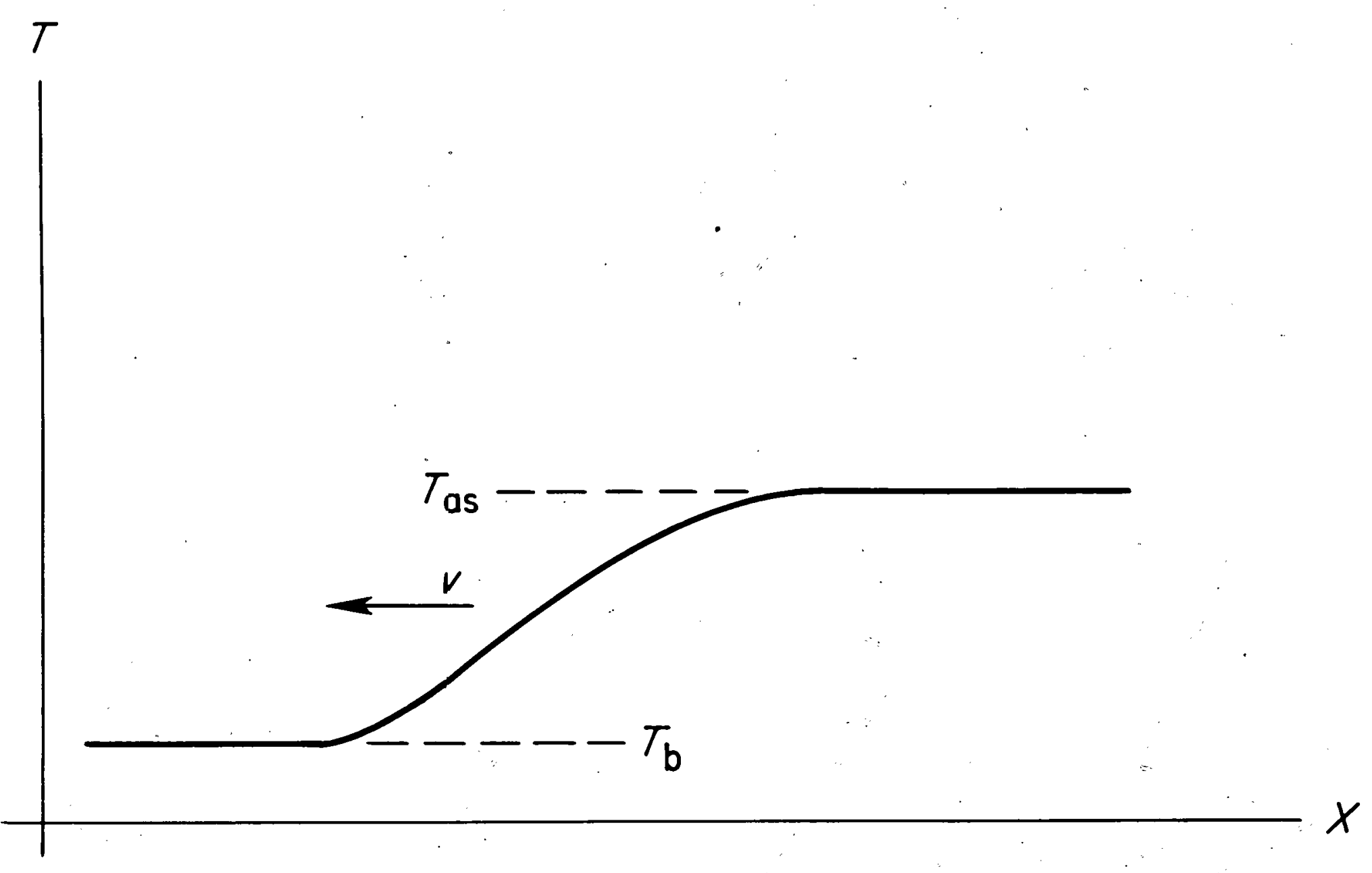

FIGURE 2 
20

ORNL-DWG 76-4272

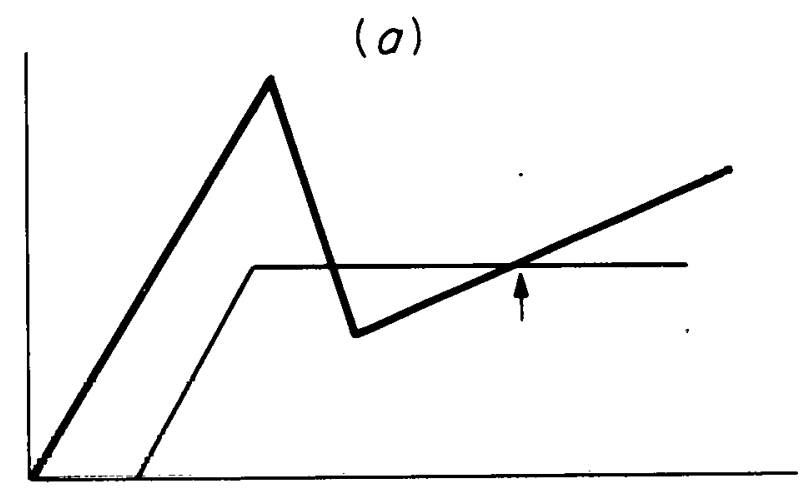

(e)
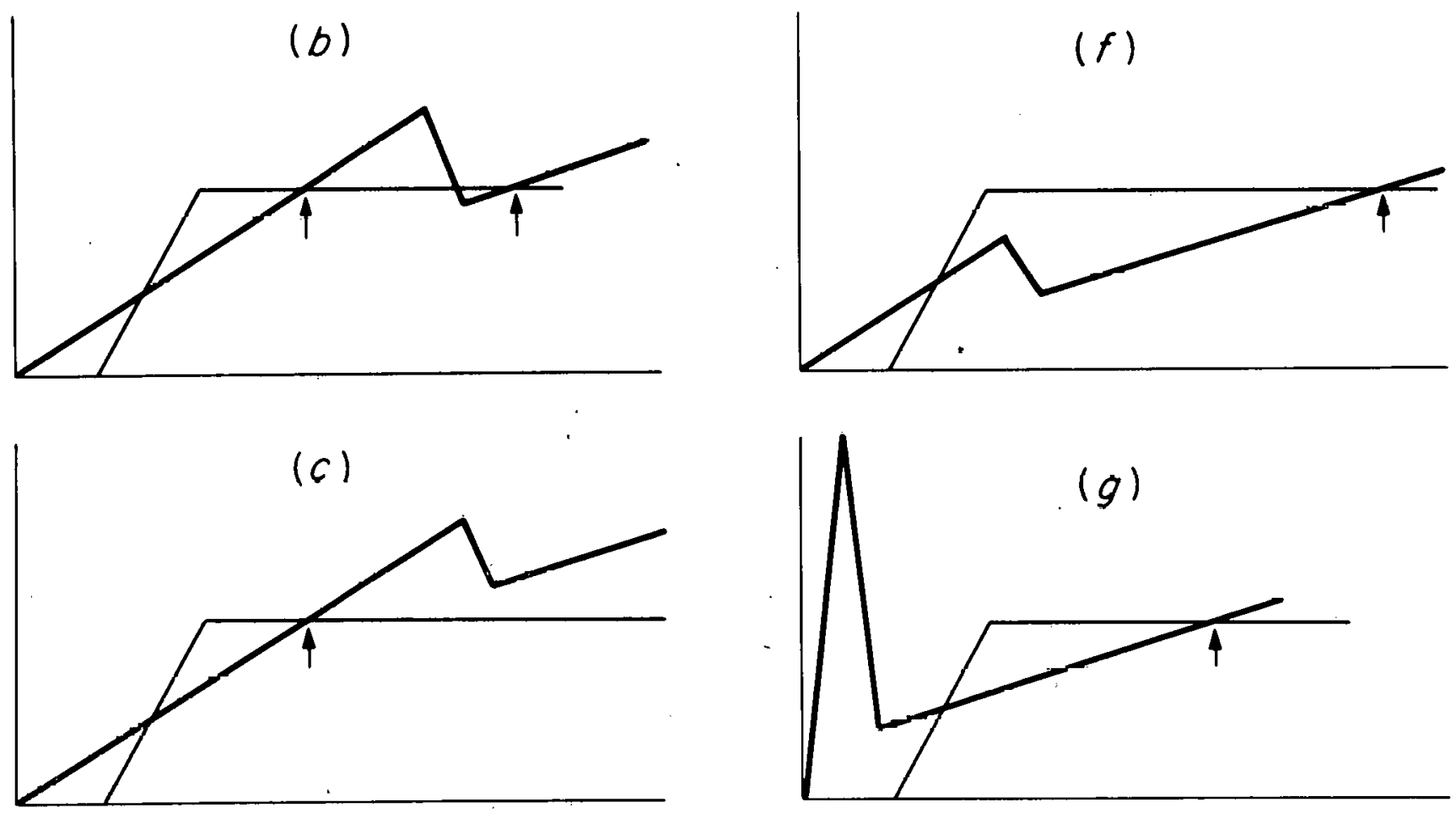

(g)
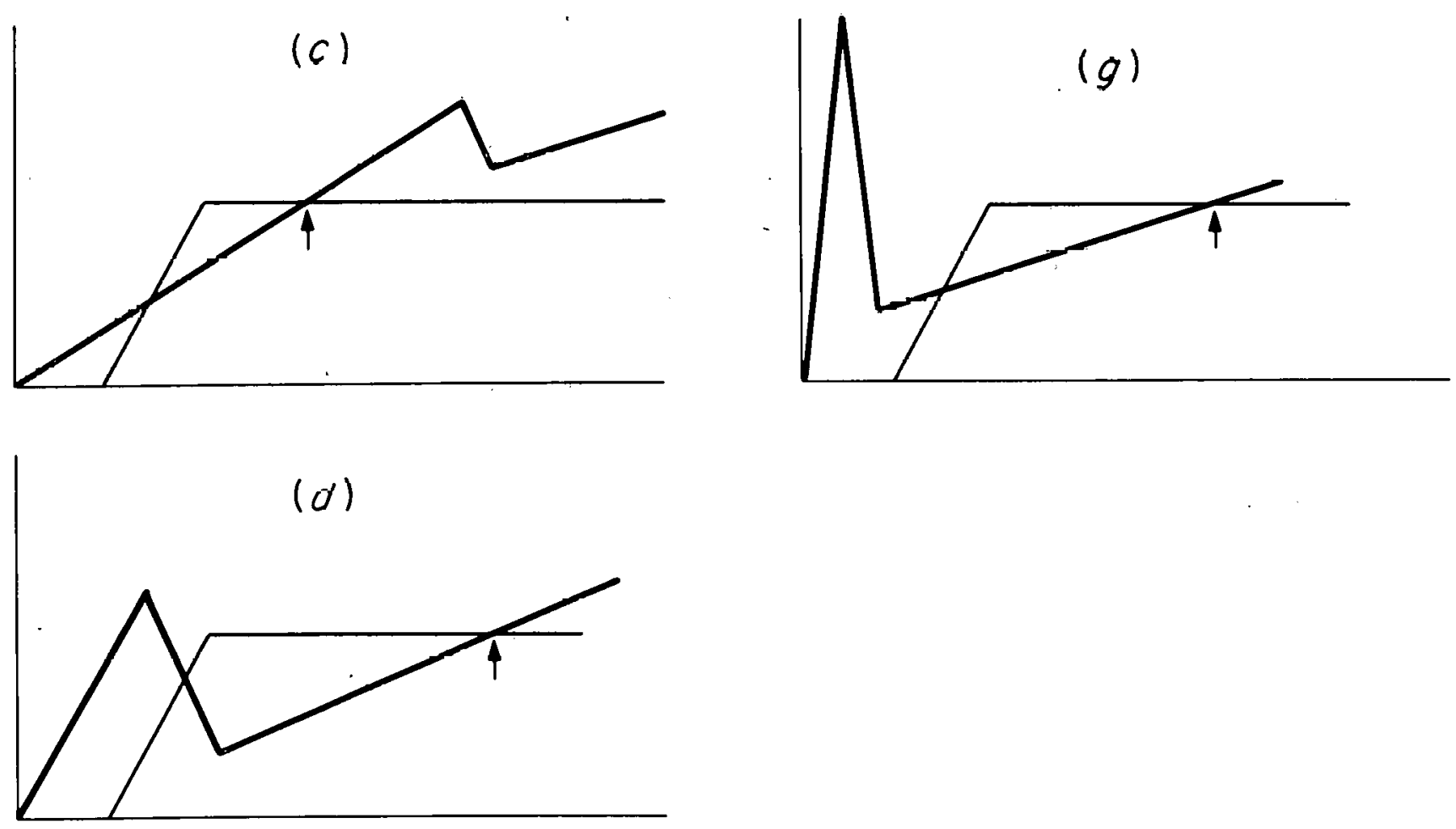

FIGURE 3 


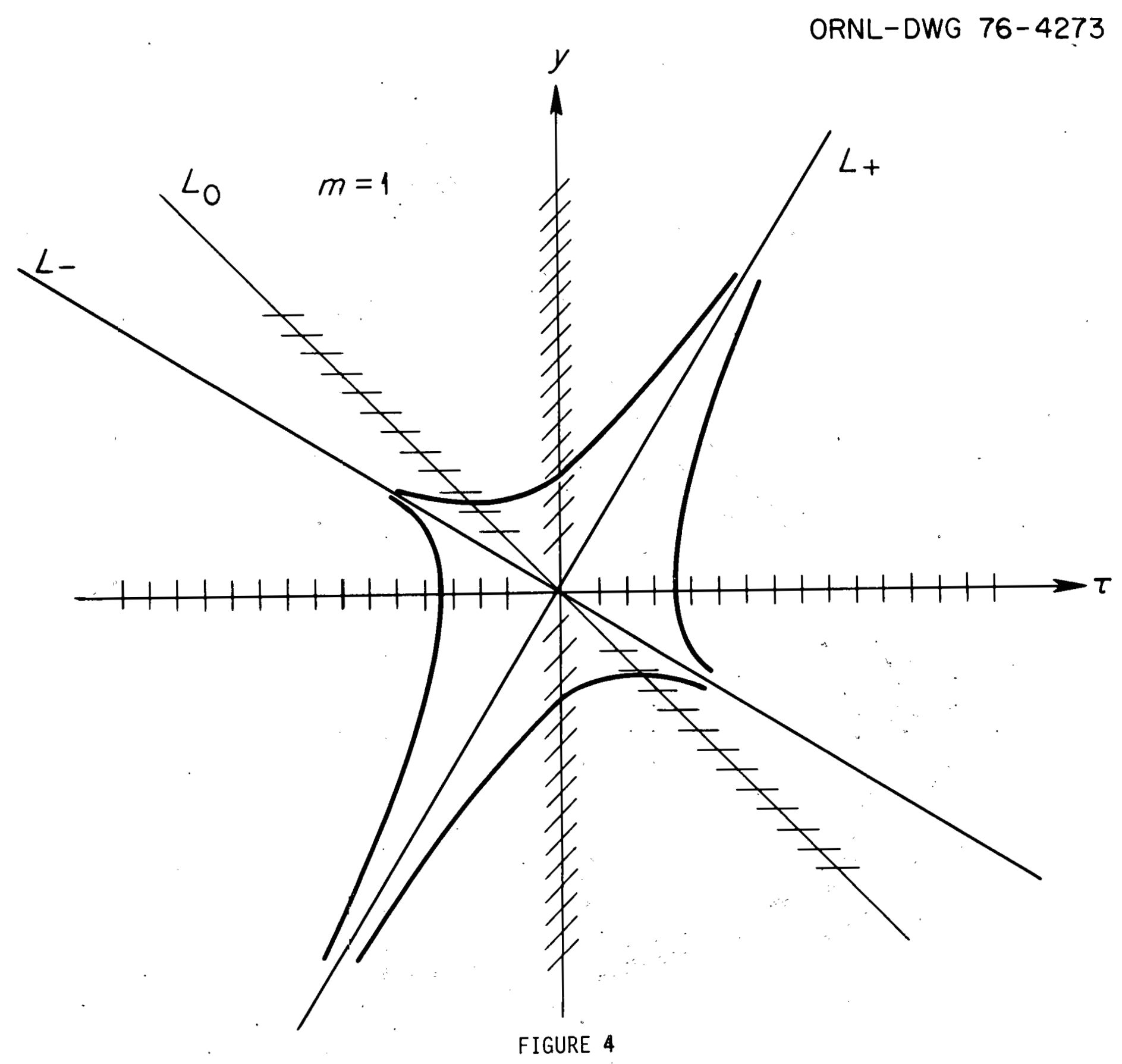




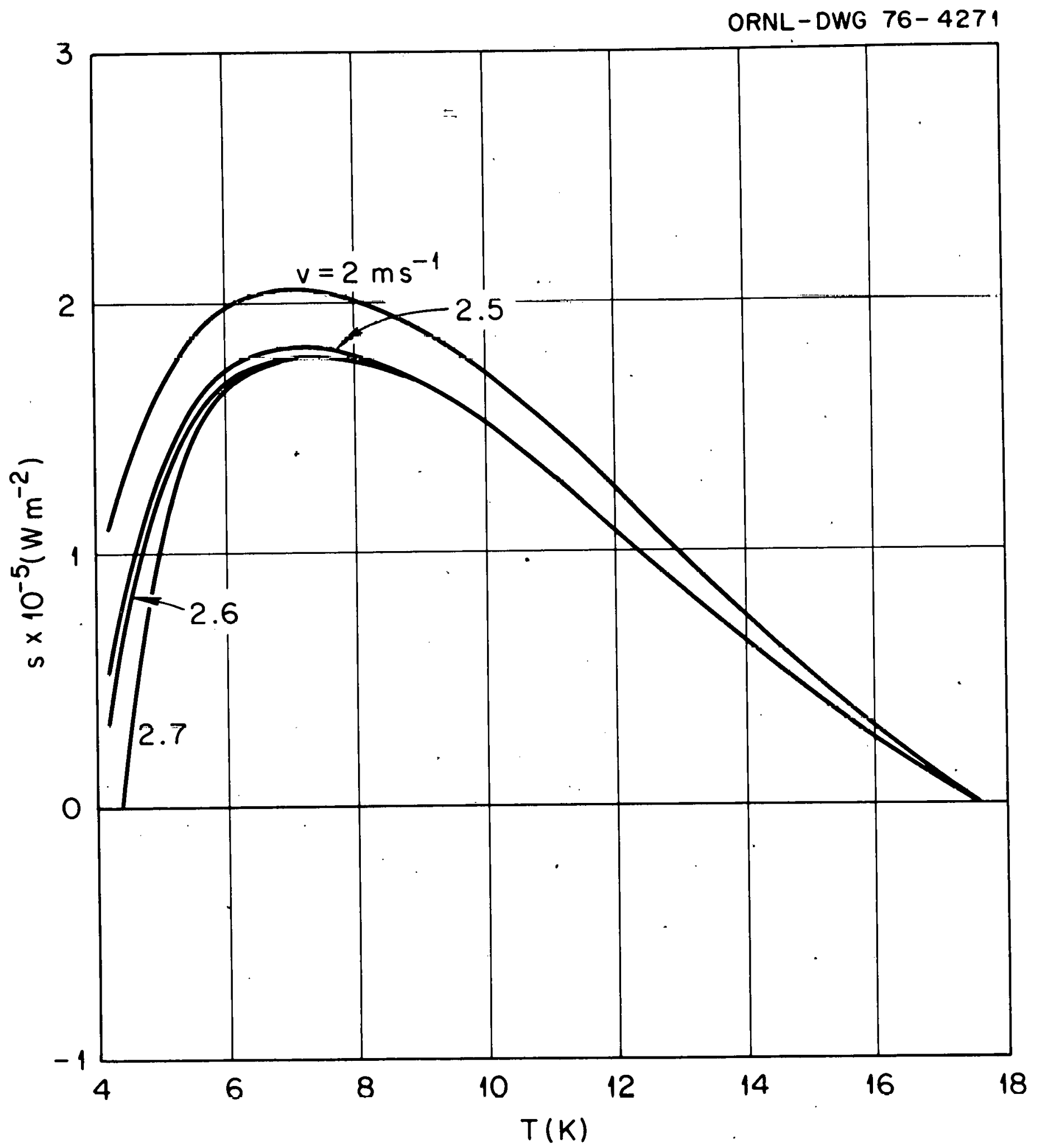

FIGURE 5 


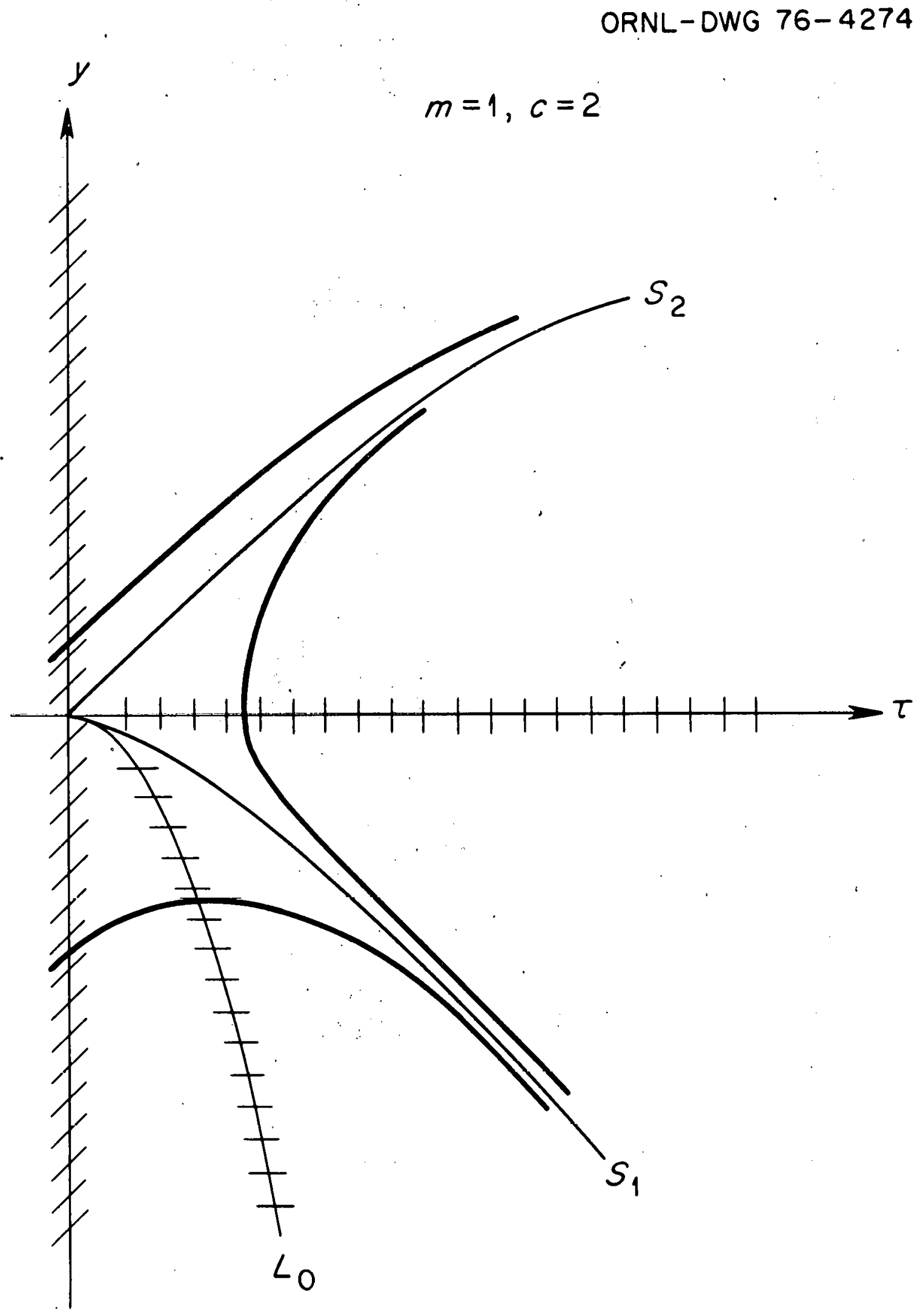

FIGURE 6 


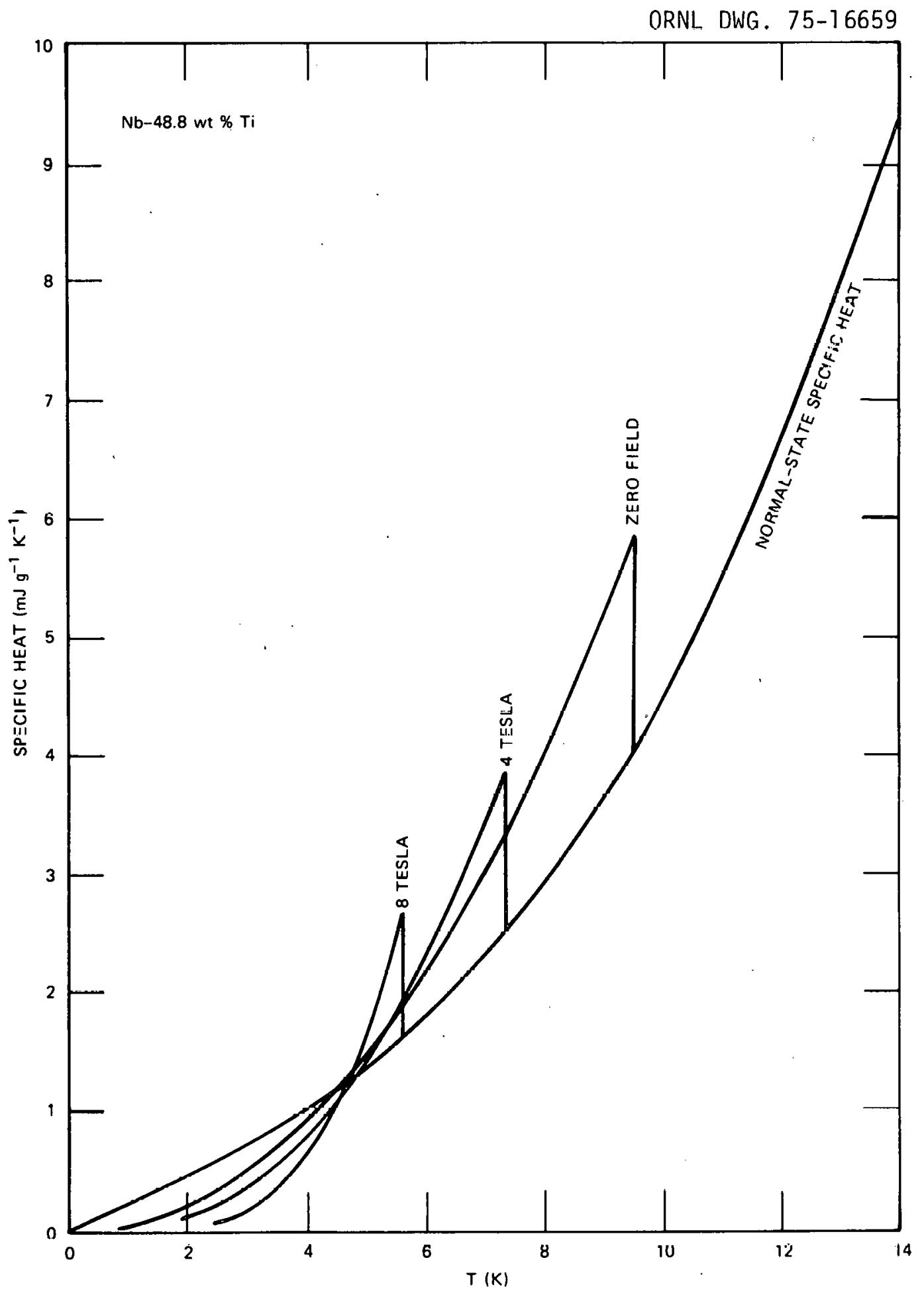

FIGURE 7 


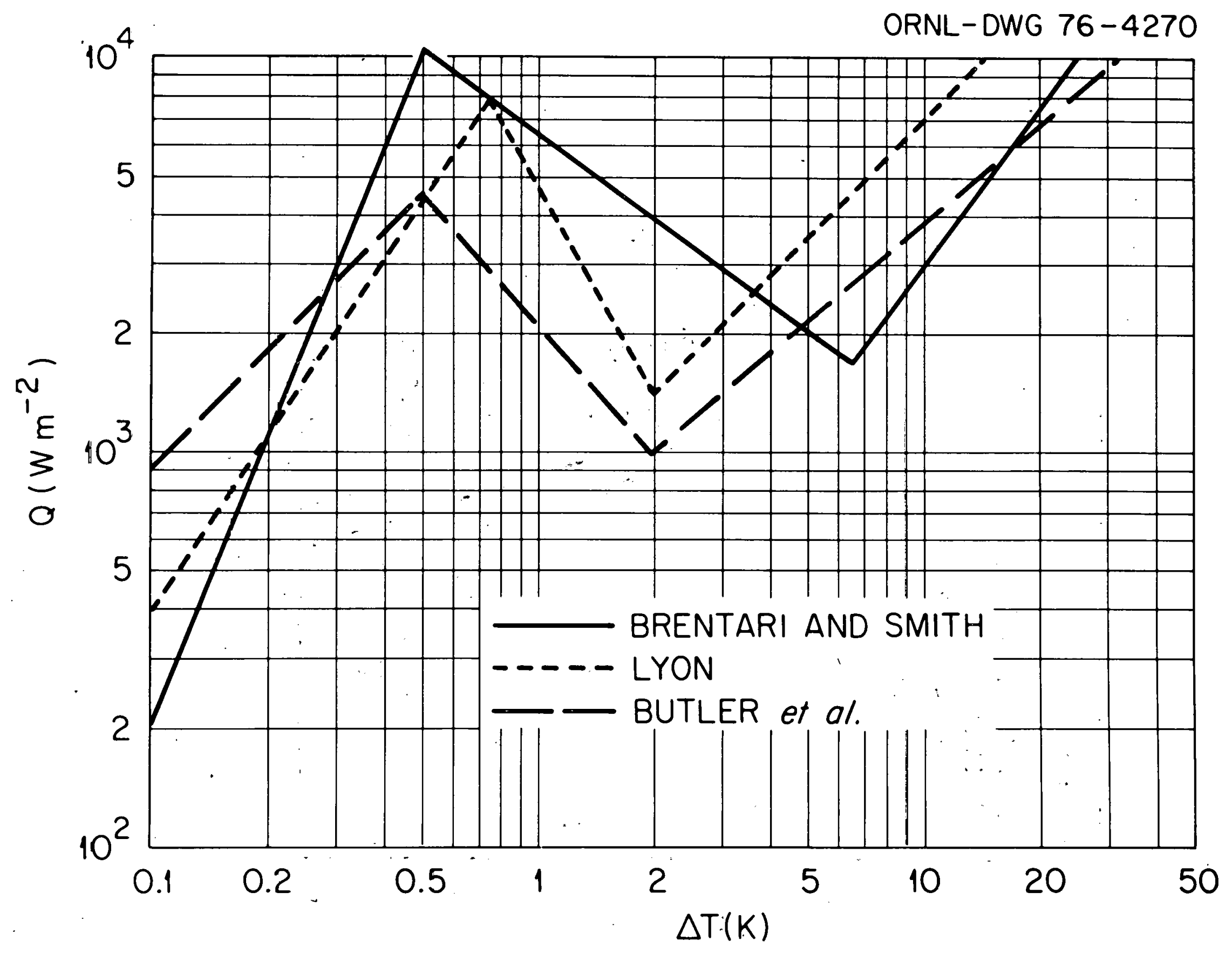


ORNL-DWG 76-4269

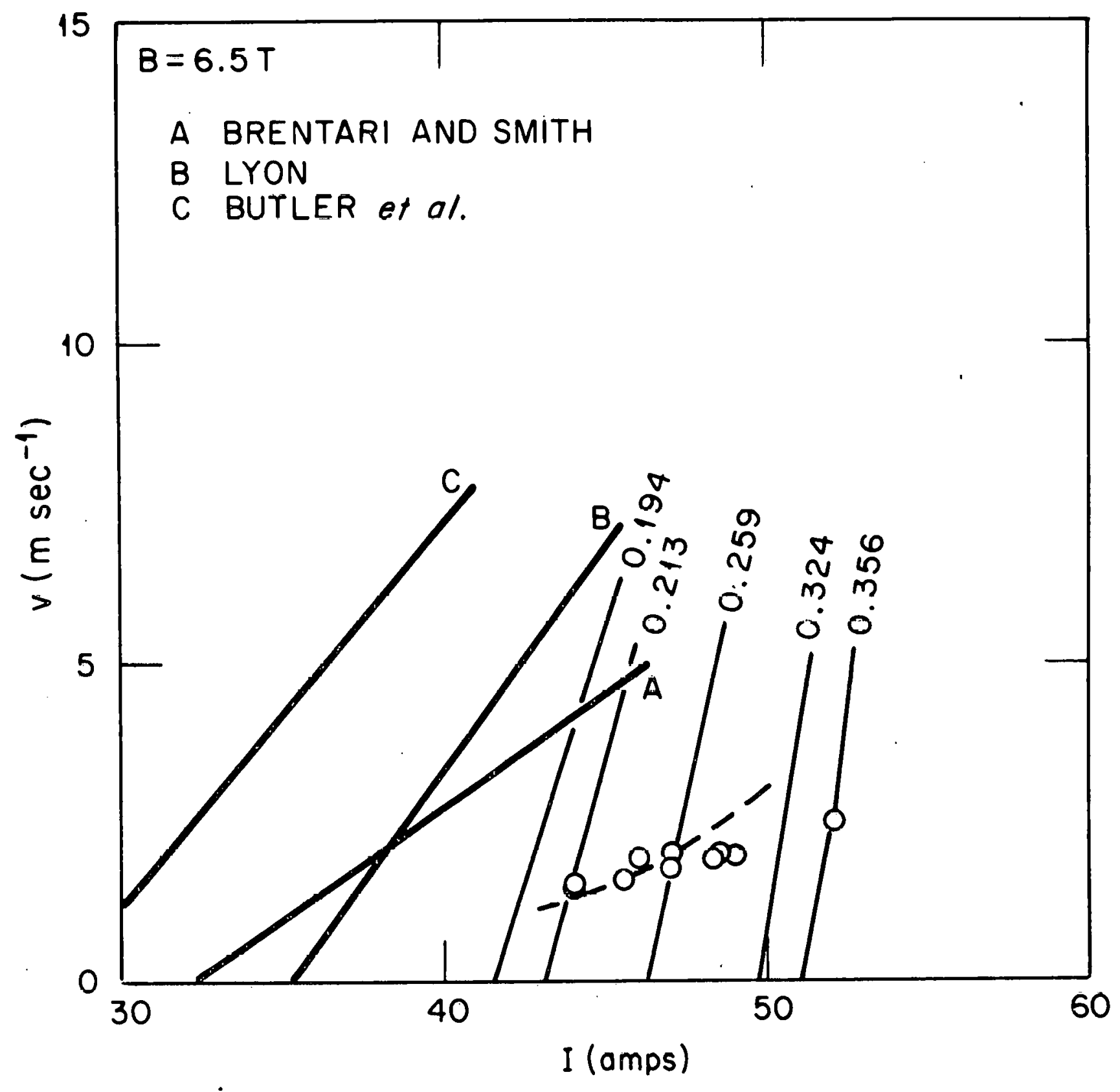

FIGURE 9 
INTERNAL DISTRIBUTION

$\begin{array}{ll}\text { 1. } & \text { W. C. Anderson } \\ \text { 2. } & \text { J. K. Ballou } \\ \text { 3. } & \text { R. L. Brown } \\ \text { 4. } & \text { E. H. Bryant } \\ \text { 5. } & \text { P. B. Burn } \\ 6 . & \text { W. D. Cain } \\ \text { 7. } & \text { D. D. Cannon } \\ \text { 8. } & \text { J. F. Clarke } \\ 9 . & \text { F. L. Culler } \\ \text { 10-14. } & \text { L. Dresner } \\ 15 . & \text { J. F. Ellis } \\ 16 . & \text { W. A. Fietz } \\ 17 . & \text { A. P. Fraas } \\ 18 . & \text { K. J. Froelich } \\ 19 . & \text { W. H. Gray } \\ 20 . & \text { P. N. Haubenreich } \\ 21 . & \text { G. G. Kelley } \\ 22 . & \text { C. G. Lawson } \\ 23 . & \text { C. J. Long } \\ 24 . & \text { H. M. Long } \\ 25 . & \text { J. K. Lovin } \\ 26 . & \text { M. S. Lubell } \\ 27 . & \text { J. W. Lue } \\ 28 . & \text { J. N. Luton } \\ 29 . & \text { H. C. McCurdy }\end{array}$

30. J. R. MAller

31. R. V. Miske11

32. O. B. Morgan

33. H. Pih

34. H. Postma

35. M. Roberts

36. M. W. Rosentha1

37. R. E. Schwall

38. T. E. Shannon

39. S. S. Shen

40. J. E. Simpkins

41. D. Steiner

42. W. C. T. Stoddart

43. P. B. Thompson

44. P. L. Walstrom

45. H. T. Yeh

46. A. Zucker

47-48. C. R. Library (2)

49. CTR Reports Office

50. Document Ref. Section

51-52. Lab Records Dept. (2)

53. Lab Records, ORNL, R.C.

54. Patent office

55-56. Thermonuclear Division

Library, (2)

\section{EXTERNAL DISTRIBUTION}

57. E. Adam, Airco, 100 Mountain Avenue, Murray Hill, NJ 07974.

58. J. W. Beal, DCTR, ERDA, Mail Stop G-234, Washington, DC 20545.

59. R. W. Boom, 513 Engineering Research Building, University of Wisconsin, Madison, WI 53706.

6U. D. L. Coffey, American Magnetics Inc., P. O. Box R, Oak Ridge, TN 37830.

61. D. N. Cornish, Lawrence Livermore Laboratory, P. O. Box 808, Livermore, CA 94550.

62. M. D'Agostino, Grumman Aerospace Corp., Bethpage, NY 11714.

63. J. E. Darby, Jr., CTR Program, D208, Argonne National Laboratory, 9700 South Cass Avenue, Argonne, IL 60439.

64. R. W. Derby, 247 Third Street, Cambridge, MA 02141.

65. Director, Research \& Technical Services Division, ERDA, Oak Ridge Operations, Oak Ridge, TN 37830.

66. R. W. Fast, Manager, Experimental Facilities, National Accelerator . Laboratory, P. O. Box 500, Batavia, IL 60510.

67. J. J. Ferrante, General Electric Co., Schenectady, NY 12345.

68. J. File, Princeton University, Plasma Physics Laboratory, Princeton, NJ 08540.

69. W. S. Gilbert, Lawrence Berkeley Laboratory, University of California, Berkeley, CA 94120 . 
70. R. W. Gould, Dept. of Applied Physics, California Institute of Technology, Pasadena, CA 91109.

71. H. Grad, Courant Institute, New York University, 251 Mercer Street, New York, NY 10012 .

72. E. Gregory, Airco, 100 Mountain Avenue, Murray Hill, NJ 07974.

73. W. V. Hassenzah1, Los Alamos Scientific Laboratory, P. O. Box 1663 Los Alamos, NM 87544.

74. C. D. Henning, DMFE, ERDA, Mail Stop G-234, Washington, DC 20545.

75. G. K. Hess, DMFE, ERDA, Mail Stop G-234, Washington, DC 20545.

76. C. K. Jones, Manager, Cryogenic Research Laboratory, Westinghouse Electric Corporation, R \& D Center, Pittsburgh, PA 15235.

77. E. E. Kintner, DMFE, ERDA, Mail Stop G-234, Washington, DC 20545.

78. H. L. Laquer, Los Alamos Scientific Laboratory, P. O. Box 1663, Los Alamos, NM 8/344.

79. C. Laverick, 543 Hampshire Lane, Boling Brook, IL 60439.

80. J. A. Mayhal1, Lockheed, P. O. Box 1103, Huntsville, AL 35807.

81. D. B. Montgomery, MIT, National Magnet Laboratory, 170 Albany Street, Cambridge, MA 02139.

82. F. Moon, Dept. of Theoretical \& Applied Mechanics, Cornell University, Tthaca, NY 14850.

83. R. W. Moses, Jr., University of Wisconsin, Madison, WI 53706.

84. J. R. Powell, Brookhaven National Laboratory, Upton, NY 11973.

85. J. R. Purcell, General Atomic Company, P. 0. Box 81608, San Diego, CA 92138 .

86. P. Reardon, PPPL, Princeton Univ., P. 0. Box 451, Princeton, NJ 08540.

87. J. D. Rogers, Q-26, Los Alamos Scientific Laboratory, P. 0. Box 1663, Los Alamos, NM 87544.

88. D. J. Rose, Dept. of Nuclear Engineering, Massachusetts Institute of Technology, Cambridge, MA 02139.

89. C. H. Rosner, Intermagnetics General Corp., Charles Industrial Park, New Karner Road, Guilderland, NY 12084.

90. W. B. Sampson, Brookhaven National Laboratory, Upton, Long Island, NY 11973.

91. Z. J. J. Stekly, Magnetic Corporation of American, 179 Bear Hill Road, Waltham, MA 02154.

92. B. P. Strauss, Fermi National Accelerator Laboratory, P. O. Box 500 , Batavia, IL 60510.

93-119. TIC, Oak Ridge, TN 37830. (27)

120. C. E. Taylor, Lawrence Livermore Laboratory, P. O. Box 808, L-384 Livermore, CA 94551.

121. R. Thomas, General Atomic Company, P. O. Box 81608, San Diego, CA 92138 .

122. C. von Keszycki, Grumman Aerospace Corp., Research Center, Building 26, Bethpage, NY 11714.

123. S. T. Wang, Argonne National Laboratory, 9700 South Cass Avenue, Argonne, IL 60439.

124. J. M. Williams, DMFE, ERDA, Ma11 Stup G=234, Washington, DC 20545.

125. J. Wong, Supercon, Inc., 9 Erie Drive, Natick, MA 01760.

126. H. H. Woodson, Chairman, Dept. of Electrical Engineering, University of Texas at Austin, Austin, TX 78712.

127. E. J. Ziurys, DMFE, ERDA, Mail Stop G-234, Washington, DC 20545. 